Dobss, R. H. (1935): Acute Pancreatitis in Childhood, Lancet, ii, 989.

Duncan, N. A. (1948): Pancreatitis due to Ascariasis, Brit. med. Y., i, 905 . Child., 27, 192.

Gibson, J. M., and Gibson, J. M., Jr. (1956): Acute Hæmorrhagic Pancreatitis in Childhood, Pediatrics, 48, 486.

HerzoG, E. (1929): Quoted by Stickler and Yonemoto. London: Pitman Medical.

Klatskin, G., and GoRdoN, M. (1952): Relationship between Relapsing Pancreatitis and Essential Hyperlipæmia Amer. F. Med., 12, 2.

MarCZYNSKA-RobowSKA, M. (1957), Pancreatic Necrosis in a Case of Still's Disease, Lancet, i, 81 5 .

Molander, D. W., and Bell, E. T. (1946): Relation of Cholelithiasis to Acute Hæmorrhagic Pancreatitis, Arch. Path 4I, I7.

Nothman, M. M. (1951): Urinary Diastase in Mumps, New Engl. F. Med., 244, 15.

Novis, I. M. S. (1923): Partial Obstruction of the Pancreatic Duct by Round Worms, Brit. F. Surg., ro, 42 I.

Poulsen, H. M. (1950): Familial Lipæmia, Acta med. scand., 138, 4 1 3.

RICH, A. R., and DUFF, G. L. (1936): Experimental and Pathological Studies in the Pathogenesis of Acute Hæmorrhagic Pancreatitis, Bull. Fohns Hopk. Hosp., 58, 212.

Sмyтh, C. J. (1940): Arch. Path., 30, 651.

StickleR, G. B., and Yonemoto, R. Y. (1958): Etiology of Acute Hæmorrhagic Pancreatitis with Special Reference to the Vascular Factors, Amer. F. Dis. Child., 95, 206.

\title{
GASTRO-ENTERIC INTUSSUSCEPTION
}

\author{
J. A. SEDdon, M.B., F.R.C.S. \\ Registrar
}

E. W. PARRY, Ch.M., F.R.C.S.
Consultant Surgeon

Bootle Hospital, Liverpool, 20

GASTRO-ENTERIC intussusception is rare and is almost always due to a benign gastric tumour, the most common being an adenomatous polyp, which may be single or multiple. Other recorded causes include leiomyoma and lipoma. Malignant lesions of the stomach are very rarely complicated by intussusception.

Hobbs and Cohen reviewed 4I cases of gastroduodenal intussusception in 1946 and only two were due to malignant lesions, one being a sarcoma and the other a carcinoma, the source of diagnosis of the latter being radiological. These appear to be the only malignant cases so far described.

Childs and Braunstein in I953 described a case due to leiomyoma of the stomach and presenting with severe epigastric pain and melæna. Riccobono and Haskins in 1960 recorded two cases of gastroduodenal intussusception, one being caused by benign gastric polyposis and the other by a leiomyoma.

\section{Classification}

(a) The intussusception may be partial or complete according to whether the mucosa alone or the whole thickness of the stomach wall is involved.

(b) The intussusception may be central or lateral.

In the central type the whole circumference of a portion of the stomach is invaginated into the duodenum so that the axis of invagination is parallel to the alimentary axis.
In the lateral type a funnel-shaped invagination is present, the axis being at an angle to the alimentary axis.

(c) It may also be classified into four gradesڤ according to the part of the duodenum the apex of $\stackrel{\mathbb{Q}}{\circ}$ the intussusception occupies.

\section{Clinical Manifestations}

The initial symptoms are those of the original gastric lesion.

When intussusception supervenes, post-prandial epigastric pain, nausea and vomiting occur due to obstruction. Hæmatemesis and melæna may also 3 . occur due to ulceration or strangulation. The symptomatology can be punctuated by sudden $\frac{3}{3}$ bouts of severe vomiting due to the ball-valve action of the intussusception. A mass may be을 palpated in the epigastrium, but this can be an inconstant finding, possibly due to intermittent spontaneous reduction of the intussusception.

\section{Radiology}

The criteria of diagnosis, as established by Schmitt and recorded by Hobbs and Cohen are:

(I) A central area of translucency in the bulbo with foreshortening of the antrum. This is caused ${ }_{\bar{\Phi}}^{\tau}$ by the intussusception preventing the accumulation $\stackrel{\oplus}{?}$ of barium.

(2) Converging axial striations present in the $\frac{0}{0}$ 

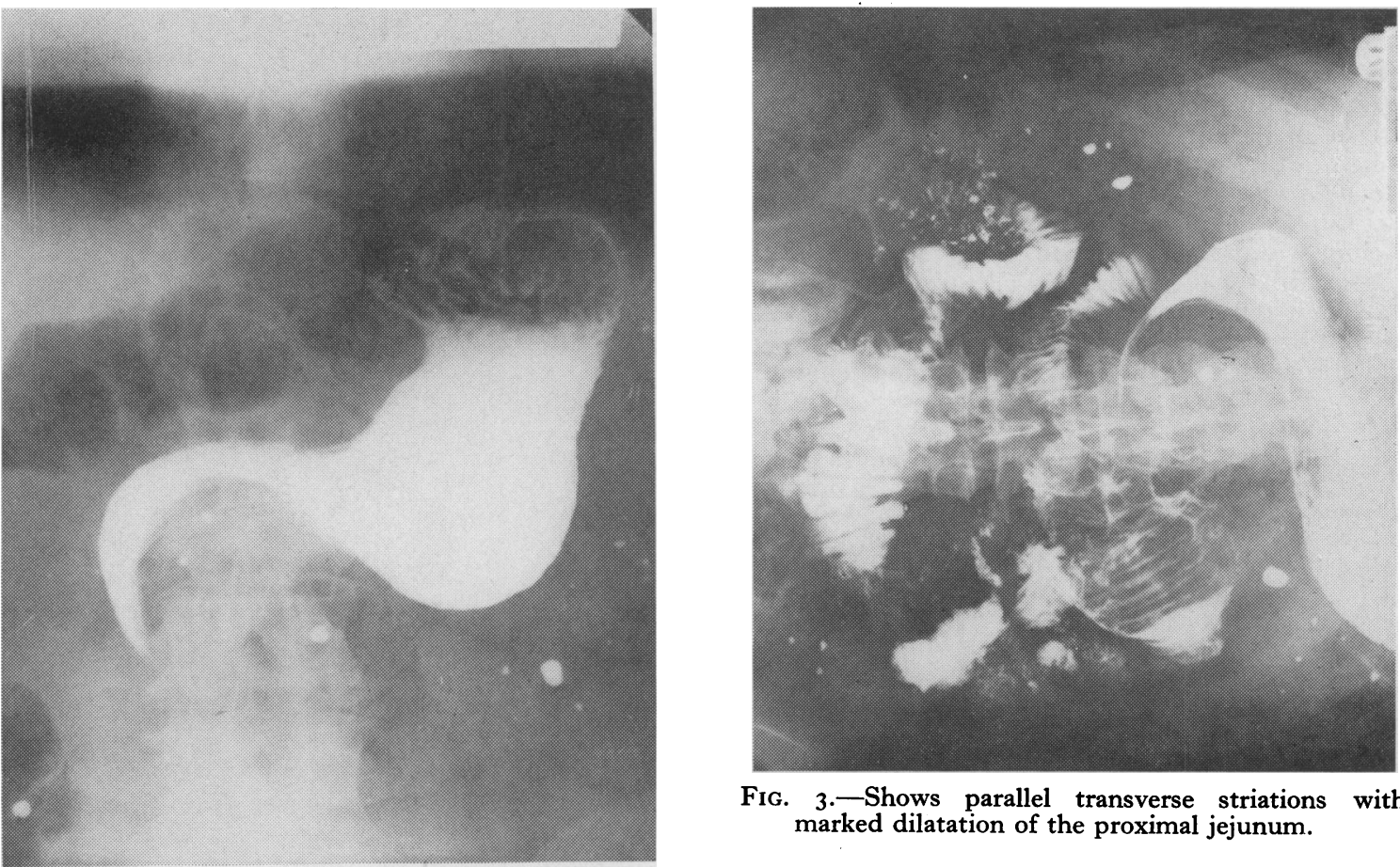

Fig. 1.-Foreshortening of the antrum with attenuation

Fig. 3.-Shows parallel transverse striations with marked dilatation of the proximal jejunum. of the duodenum is shown.
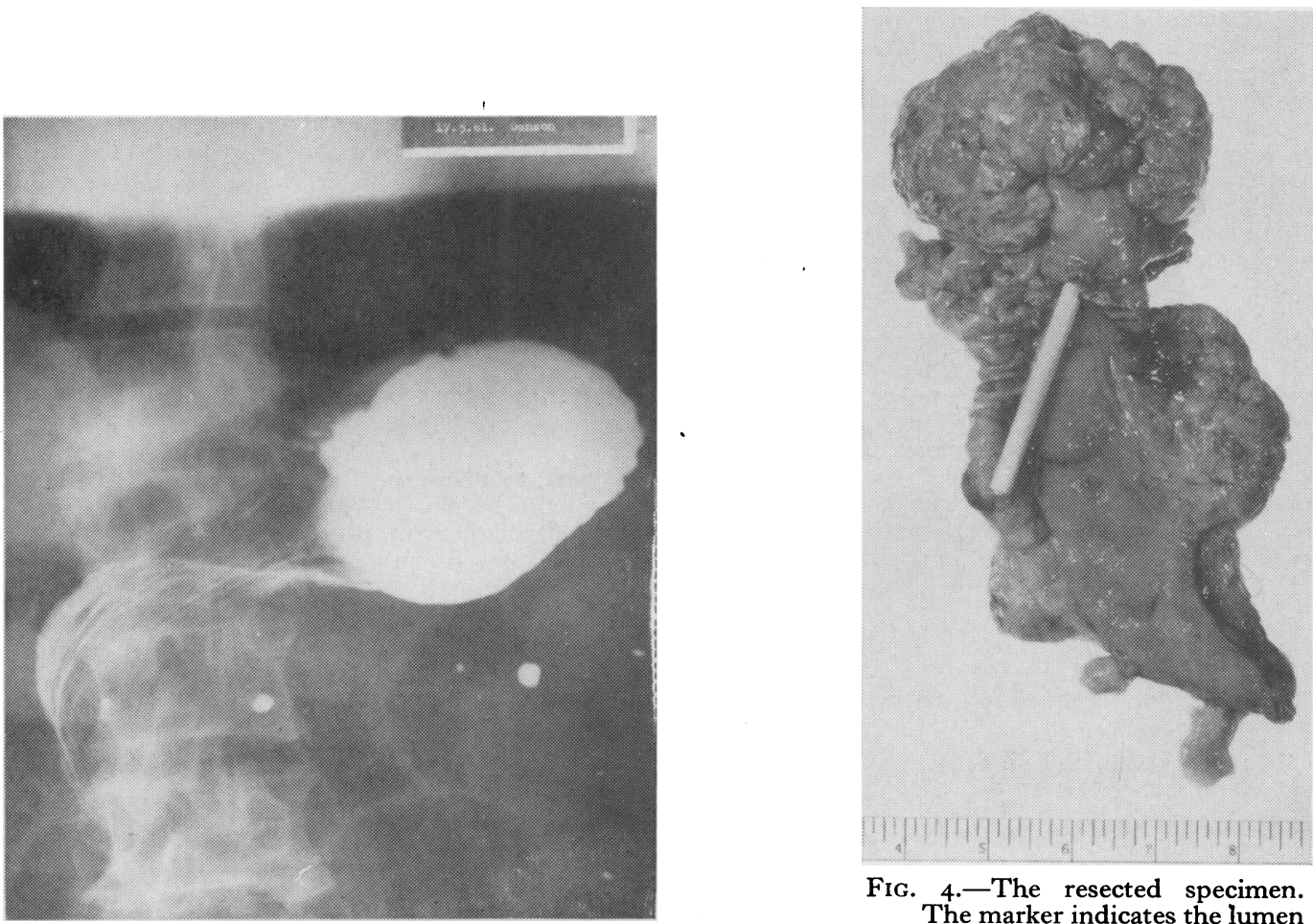

Fig. 2.-Converging axial striations are present.

Fig. 4.-The resected specimen. The marker indicates the lumen of the intussusception. 
stomach and duodenum. The striations are longitudinal and parallel to the long axis of the gut. They are due to tension on the gastric wall as it is drawn into the duodenum and are represented by streaks of barium within the mucosal folds in the lumen of the intussusception.

(3) Parallel transverse striations running perpendicular to the axial striations. They are due to barium within the lumen of the intussuscipiens.

The following case-history illustrates the above features. It is somewhat unique in that the intussusception was due to a malignant gastric lesion and the intussusceptum had entered the jejunum.

\section{Case Report}

E. B., male, aged 74, first seen in October 1960, complaining of increasing lassitude over the previous six months. Apart from pallor of the skin and mucous membranes, there were no abnormal clinical findings.

Investigations. Hb. $55 \%$, r.b.c. $2.8 \mathrm{million} / \mathrm{cu}$. $\mathrm{mm}$., w.b.c. $12,800 /$ cu.mm. X-ray of chest: no significant pulmonary pathology. Examination of the stools showed a trace of occult blood, but further examinations gave negative results. A barium meal showed no abnormality. Sternal marrow biopsy: no significant feature. Fractional test meal: achlorhydria.

He was given a course of iron therapy and markedly improved. In April 196I he commenced having intermittent attacks of epigastric discomfort and vomiting, and an indefinite mass was palpated in the epigastrium on one occasion, but was not evident at subsequent examinations.

The investigations were repeated. Barium meal showed the characteristic features described above, and in addition there was marked attenuation of the duodenum with dilatation of the proximal jejunum (Figs. I, 2 and 3). Hb. $41 \%$. A large amount of occult blood was present in the stools.

A laparotomy was carried out through a right paramedian incision. A large mass was palpated in the proximal jejunum and demonstrated to be due to a gastric intussusception. The proximal jejunum was greatly dilated. Areas of fat necrosis were also noted. The intussusception was reduced to the second part of the duodenum, but could not be reduced further. The duodenum was then opened, revealing a large nodose tumour of the stomach.

The stomach was everted and the duodenum was divided and closed. Multiple glandular metastases were present along both curvatures. However, the liver was apparently clear and there were no peritoneal metastases. Extended partial gastrectomy was then performed.

Post-operatively, the patient made satisfactory progress for ten days and then developed massive odema of the lower limbs and lumbar sacral area, almost cer-

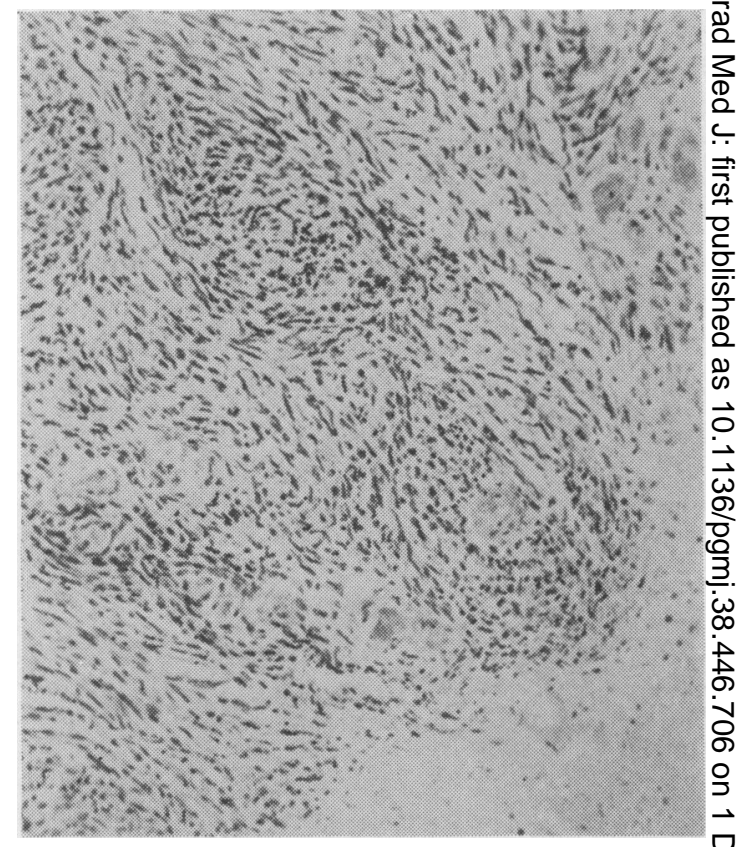

Fig. 5.-Photomicrograph showing the histology of the्D leiomyosarcoma.

tainly due to inferior vena caval thrombosis. A fow days later he developed acute renal failure and died

Permission for autopsy was not granted and we we thus unable to confirm the cause of death.

\section{Pathology}

The specimen, as shown, confirms that thes intussusception was a complete, central type and an extended Grade IV (Fig. 4). Histological examina tion showed the lesion to be a leiomyosarcoma (Fig. 5).

\section{Summary}

A case of gastro-enteric intussusception due tô leiomyosarcoma of stomach is presented.

The classical symptomatology and radiologica findings have been outlined and the classification. of gastro-enteric intussusception has been reiterated $\frac{3}{3}$

We wish to thank the Radiological and Pathologica Departments of Bootle Hospital, the Central Photo graphic Department of Liverpool University, and $\mathrm{Dr}_{\mathrm{O}}$ D. B. Macaulay for permission to publish this case.

\section{REFERENCES}

Childs, C. G., and Braunstein, P. W. (1953): Gastroduodenal Intussusception, with Massive Hæmorrhage, Surgery 34, 754 .

HoBbs, W. H., and CoHEN, S. E. (1946): Gastroduodenal Invagination due to a Submucous Lipoma of the Stomach
Amer. F. Surg., 71, 505.

Riccobono, X. J., and HaSkins, R. M. (1960): Gastroduodenal Intussusception, Gastroenterology, 38, 995. 